\title{
Tubal Pregnancy
}

National Cancer Institute

\section{Source}

National Cancer Institute. Tubal Pregnancy. NCI Thesaurus. Code C92946.

An abnormal pregnancy in which the conception is implanted in the fallopian tube. 